\title{
Water soluble Polyaniline/Polysaccharide composite: Polymerization, Carbonization to Yield Carbon Micro-bubbles
}

\author{
Kuniharu Nakajima, Kohsuke Kawabata and Hiromasa Goto* \\ Division of Materials Science, Faculty of Pure and Applied Science, University of Tsukuba, \\ Ibaraki, Japan \\ Correspondence to H. Goto \\ Tel: +81 029-853-5218 \\ E-mail address: gotoh@ims.tsukuba.ac.jp
}

\begin{abstract}
We report synthesis of water soluble polyaniline composite using polysaccharide, alginic acid, by oxidative chemical polymerization. Spectroscopy measurements for the composites with infrared (IR), UV-vis spectroscopy, electron spin resonance (ESR), and scanning electron microscopy (SEM) were carried out. We confirmed water solubility of the composite and carbonization allowed the composite to form carbon micro-bubble structures.
\end{abstract}

Keywords: polyaniline, polysaccharide, alginic acid, composite, absorption spectrum, conjugated polymer

\section{INTRODUCTION}

Conducting polymers [1] have raised great interest because of their many possible applications [2]. Among them, polyaniline (PANI) has been also carried out on many studies such as polymerization mechanism, reversibility in the doping/dedoping process, and chemical stability [3-7]. Many kinds of polyaniline composites with organic/inorganic acid [2,8-11], minerals [12-14], or metals [15,16] have been reported about their properties (ie. dichroism, solublity in various solvents, formation of fiber/tube/sphere nano structures $[17,18])$. Besides, carbonized polyaniline has been studied [19]. Polyaniline maintains the fine structure after carbonization. Recently, conjugated polymer composite using shizophyllan ( $\beta$-1,3-glucan) for wrapping onto the polymer chain has been reported [20]. The composite material shows unique properties. Here, we report synthesis and carbonization of polyaniline composites using alginic acid.

\section{EXPERIMENTAL}

\subsection{Materials}

Aniline (Wako Chemical, Japan) was purified by distillation. Alginic acid, $\mathrm{N}$-methylpyrrolidone (NMP) (Tokyo Chemical Industry, Japan), ammonium persulfate (APS, $\left(\mathrm{NH}_{4}\right)_{2} \mathrm{~S}_{2} \mathrm{O}_{8}$ ) (Kanto chemical, Japan) were used as received.

\subsection{Instruments}

Infrared (IR) absorption spectra for the polymers were obtained using a JASCO IR 550 Fourier transform spectrometer (Japan) with the $\mathrm{KBr}$ method. Ultra visible (UV-vis) spectra were recorded on a JASCO V-630 spectrophotometer. Electron spin resonance (ESR) measurements were carried out using a JEOL JES TE-200 (Japan) spectrometer with $100 \mathrm{kHz}$ 
SYNTHETIC METALS, 194, 47-51(2014)

Water soluble polyaniline/polysaccharide composite: Polymerization, carbonization to yield carbon micro-bubbles

modulation. Scanning electron microscopy (SEM) observations and energy dispersive X-ray spectrometry (EDS) were performed with a JEOL JSM-521 (Japan).

\subsection{Preparation of Polyaniline composites}

Aniline (1 g, $11 \mathrm{mmol})$ and alginic acid $(0.5,1,1.5 \mathrm{~g})$ were added to distilled water $(100 \mathrm{~mL})$ in an Erlenmeyer flask. The solution was stirred for $3 \mathrm{~h}$ and cooled to $0{ }^{\circ} \mathrm{C}$. Then, APS $(1.2 \mathrm{~g}$, $5.3 \mathrm{mmol}$ ) was added into the flask, and stirred further $48 \mathrm{~h}$ at $0^{\circ} \mathrm{C}$. The mixture was filtered, and washed with a large volume of water/methanol in several times. After filteration, the cake like compounds was collected and dried in a vacuum for $6 \mathrm{~h}$. We obtained three samples with different of PANI/alginic acid ratio. The composites are abbreviated as APC.

\subsection{Carbonization of Polyaniline composite}

Carbonization of the composites was carried out under argon flow for $1 \mathrm{~h}$ at $900^{\circ} \mathrm{C}$. Yield of carbonized PANI was 44\% and carbonized APC1, APC2, and APC3 were 32, 22, and 31\% respectively.

\section{RESULTS AND DISCUSSION}

\subsection{IR absorption spectra}

Figure 1 shows IR spectra of as prepared PANI $\left(\mathrm{H}_{2} \mathrm{SO}_{4}\right.$ doped) and the APC 1-APC3. The polyaniline shows some characteristic bands at $1552 \mathrm{~cm}^{-1}\left(v_{\mathrm{Q}}\right)$ and $1473 \mathrm{~cm}^{-1}\left(v_{\mathrm{B}}\right)$, which are ascribed to $\mathrm{C}=\mathrm{C}$ stretching vibration of quinonoid (Q) and benzenoid (B) structures. The absorption bands at $1300 \mathrm{~cm}^{-1}\left(v_{\mathrm{QBQ}}\right)$ and $1240 \mathrm{~cm}^{-1}\left(v_{\mathrm{BBB}}\right)$ are due to $\mathrm{C}-\mathrm{N}$ stretching absorption of QBQ and BBB structures, respectively [21]. Moreover, the absorption bands at $1730 \mathrm{~cm}^{-1}\left(v_{\mathrm{C}=\mathrm{O}}\right)$ and $1033 \mathrm{~cm}^{-1}\left(v_{\mathrm{C}-\mathrm{O}}\right)$ are assigned to carboxyl group and glycoside bond of alginic acid, respectively. Absorption bands at long wavelength are well known as characteristic bands of PANI.

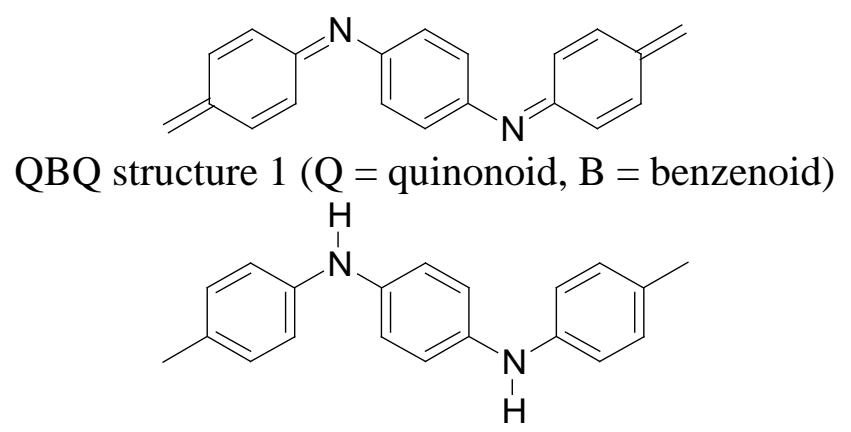

BBB structure 2

The series of APCs show the characteristic bands. The composites shows absorption bands at 1577 (Q) and $1489 \mathrm{~cm}^{-1}(\mathrm{~B})$, in place of 1552 (Q) and $1473 \mathrm{~cm}^{-1}$ (B) of the pure PANI. The absorption bands shift can be due to transformation of quinonoid rings to a more benzenoid rings [22]. Because carboxyl group of alginic acid can play a role of dopant additionally [23]. In general, nitrogen atom of polyaniline is doped with sulfate ion, this can be referred to as primary doping. However, in this research, the PANI is doped by both sulfuric acid and alginic acid. In other words, double doping for polyaniline is occurred in this case. The double doping allows the PANI to form the emeraldine salt in the composite. On the other hand, 
SYNTHETIC METALS, 194, 47-51(2014)

Water soluble polyaniline/polysaccharide composite: Polymerization, carbonization to yield carbon micro-bubbles

intensity ratio of the two bands $\left(1577 \mathrm{~cm}^{-1} / 1489 \mathrm{~cm}^{-1}\right)$ is slightly increased with the amount of alginic acid in the APCs. These results indicate that the material thus synthesized is a form of composite of PANI and alginic acid, and have electronic interaction between PANI and alginic acid in the composites (Fig. 2).

Fig. 1.

Fig. 2.

\subsection{UV-vis spectra}

Figure 3 displays UV-vis spectra of the PANI and the composites in NMP solution. The absorption band at $325 \mathrm{~nm}$ is due to $\pi-\pi^{*}$ transition of benzene ring, and the absorption band at $627 \mathrm{~nm}$ is ascribed to doping band derived from quinonoid structure. A series of the absorption spectra of the APCs in NMP solution showed doping band at around $620 \mathrm{~nm}$ (Fig. 3). On the other hand, the APCs in water solution (Fig. 4) show different absorption bands from the absorption bands in the NMP. The solubility of the composite in water is better than that in organic solvent (Supporting information, Tables S4 and S5). In addition, previous researches reported optical absorption of dependency on $\mathrm{pH}$ values [24, 25]. Wan proposed that the absorption of doping band from quinonoid structure gradually decreases with increasing acidity ( $\mathrm{pH} 4$ to 1) [24], by contrast, a new absorption band appears at low energy region (long wavelength). Stejskal et al reported that a protonated form of PANI displays three absorption bands at around 350, 430, and $810 \mathrm{~nm}$ under a low pH condition [25]. These results can be related with acid doping to the PANIs. In the present research, the doping can be enhanced by the alginic acid in the water (Fig. 4). Intrusion of water between the polyaniline and alginic acid promotes ionization and extension of the distance between the two polymers, resulting good solubility of the composite and good static interaction between polyaniline and alginic acid (Fig. 5). The extension of the inter-chain distance produces change in the structure from compact coil to expanded coil [7]. The change in the form allows development of effective conjugation length because $\pi-\pi^{*}$ transition band of the main-chain was red shifted toward low energy region from $<400 \mathrm{~nm}$ to ca. $450 \mathrm{~nm}$. The formation of expanded coil improves both effective conjugation length and red shift of the doping band (polaron band). MacDiarmid et al reported secondary doping state. Polyaniline is doped with solvent molecule, and this induces morphology change from compact coil to expanded coil. In the case of the PANI/alginic acid composite, this is a new result of secondary doping by the polymer dopant (alginic acid as a natural polymer).

Fig. 3.

Fig. 4.

Fig. 5.

\subsection{ESR spectra}

The polyaniline has several electronic states [23]. The emeraldine salt has polarons (radical cation) units along the main-chain [7]. The formation of composite process gave two advantages for PANI, such as expanded coil formation as the secondary doping, and double doping by alginic and sulfuric acid. Figure 6 shows ESR spectra detected by the unpaired electron signal of the composites. Generally, $g$-value of electron near a nitrogen-hydrogen bond is 2.0054 and that of electron near a carbon-hydrogen bond is 2.0031 [26]. In this experiment, the $g$-values of the samples are half-position between the both values (Table 1 ). A narrow peak to peak line-width means high polaron mobility [27], indicating good delocalization of polaron in the main-chain. Large $\Delta H_{\mathrm{pp}}$ value and low spin concentrations of the composite indicate localization of polarons along the PANI, resulted in low conductivity compared to pure PANI. Furthermore, insertion of alginic acid as an insulator between the 
SYNTHETIC METALS, 194, 47-51(2014)

Water soluble polyaniline/polysaccharide composite: Polymerization, carbonization to yield carbon micro-bubbles

conductive main-chain is to be a wall for inter-chain hopping transportation of electrons.

Fig. 6.

Table 1.

\subsection{SEM images}

A pure PANI shows bulky structure in Fig. 7 (a), contrary the surface structure of the composites observable showed somewhat smooth (Fig. 7 (b,c,d)). The flatness can be derived from alginic acid composition in the composite. Higher abundance ratios of oxygen and sulfate atoms are detected in the composites (Table 2). The two elements are derived from alginic acid as a secondary dopant.

Fig. 7.

Table 2.

Figure 8 shows SEM images of the carbonized PANIs. Table 3 indicates element ratio of carbonized the composites. We conducted carbonization of composites at $900{ }^{\circ} \mathrm{C}$. Aromatic ring of PANI improve thermal stability, according to the literatures [19, 28]. Figures 7 (a) and Fig. 8 (a) indicate that the composites maintained the surface form after the carbonization. On the other hand, porous structures were observable in the carbonized samples. Clearly, porous micro-bubble structure was observed, as shown in Fig. 8 (d). The carbonization process directly converted the PANI composite to the carbons. We consider that the micro-size moisture in inside of the APCs was evaporated during carbonization, and water vapor came out from the sample inside. Then, the carbon micro-bubble structure could be created in the process of carbonization.

Fig. 8.

Table 3.

\section{CONCLUSION}

We synthesized the water soluble polyaniline composite using alginic acid through the simple method. The resultant composites have solubility in water. The secondary doping has been carried out by formation of the composites. IR absorption and EDS measurements revealed that the composite contains alginic acid and sulfuric acid as double doping dopants. SEM observation evaluated that the carbonization allowed the composite to form "carbon micro-bubble structure".

\section{REFERENCES}

[1] MacDiarmid AG, Angew. Chem. Int. Ed. Engl. 40 (2001) 2581-2590

[2] Yuan G, Kuramoto N, MacromolChem Phys. 205 (2004) 1744-1751

[3] Genies EM, Boyle A, Lapkowski M, Tsintavis C, Synth Met. 36 (1990) 139-182

[4] Pouget JP, Jozefowicz ME, Epstein AJ, Tang X, Macdiarmid AG, Macromolecules. 24 (1991) 779-789

[5] Ahmed SM, Polym. Degrad. Stab. 85 (2004) 605-614

[6] Stejskal J, Sapurina I, Trchova M, Progpolym Sci. 35 (2010) 1420-1481

[7] MacDiarmid AG, Epstein AJ, Synth Met. 65 (1994) 103-116

[8] Pawar SG, Patil SL, Chougule MA, Mane AT, Jundale DM, Patil VB, Int J Polym Mater. 59 (2010) 777-785

[9] Majidi MR, Kane-Maguire Leon AP, Wallance GG, Polymer. 18 (1995) 3597-3599

[10] Kulkarni MV, Viswanath AK, Marimuthu R, Seth T, J PolymSci A Polym Chem. 42 (2004) 2043-2049

[11] Setgeev VG, Lokshin NA, Golubev VB, Zezin AB, Levon K, DoklPhys Chem. 390 


\section{SYNTHETIC METALS, 194, 47-51(2014) \\ Water soluble polyaniline/polysaccharide composite: Polymerization, carbonization to yield \\ carbon micro-bubbles}

(2003) 118-121

[12] Goto H, J. Hot Spring Sci. 60 (2010) 134-144

[13] Ciric-Marjanovic G, Dondur V, Milojevic M, Mojovic M, Mentus S, Radulovic A, Vukovic Z, Stejskal J, Langmuir. 25 (2009) 3122-3131

[14] Ciric-Marjanovic G, Dragicevic L, Milojevic M, Mojovic M, Mentus S, Dojcinovic B, Marjanovic B, Stejskal J, J Phys Chem B. 113 (2009) 7116-7127

[15] Genoud F, Kulszewicz-Bajer I, Bedel A, Oddou JL, Jeandey C, Pron A, Chem Mater. 12 (2000) 744-749

[16] Bober P, Trchova M, Prokes J, Varga M, Stejskal J, Electrochim Acta. 56 (2011) 3580-3585

[17] Goto H, Yokoo A, J Dispers Sci Technol. 34 (2013) 406-410

[18] Konyushenko EN, Stejskal J, Sedenkova I, Trchova M, Sapurina I, Cieslar M, Prokes J, Polym Int. 55 (2006) 31-39

[19] Mentus S, Ciric-Marjanovic G, Trchova M, Stejskal J, Nanotechnology. 20 (2009) 245601

[20] Numata M, Shinkai S, Chem. Commun. (Camb.). 47 (2011) 1961-1975

[21] Tang J, Jing X, Wang B, Wang F, Synth Met. 24 (1988) 231-238

[22] Trchova M, Stejskal J, Prokes J, Synth Met. 101 (1999) 840-841

[23] Macdiarmid AG, Chiang JC, Richter AF, Synth Met. 18 (1987) 285-290

[24] Wan M, J PolymSci A Polym Chem. 30 (1992) 543-549

[25] Stejskal J, Kratochvil P, Synth Met. 61 (1993) 225-231

[26] Kahol PK, Pinto NJ, Solid State Commun. 124 (2002) 195-197

[27] Yang SM, Chen KH, Yang YF, Synth Met. 152 (2005) 65-68

[28] Kijima M, Tanimoto H, Takakura K, Fujiya D, Ayuta Y, Matsuishi K, Carbon. 45 (2007) 594-601 


\section{SYNTHETIC METALS, 194, 47-51(2014)}

Water soluble polyaniline/polysaccharide composite: Polymerization, carbonization to yield carbon micro-bubbles

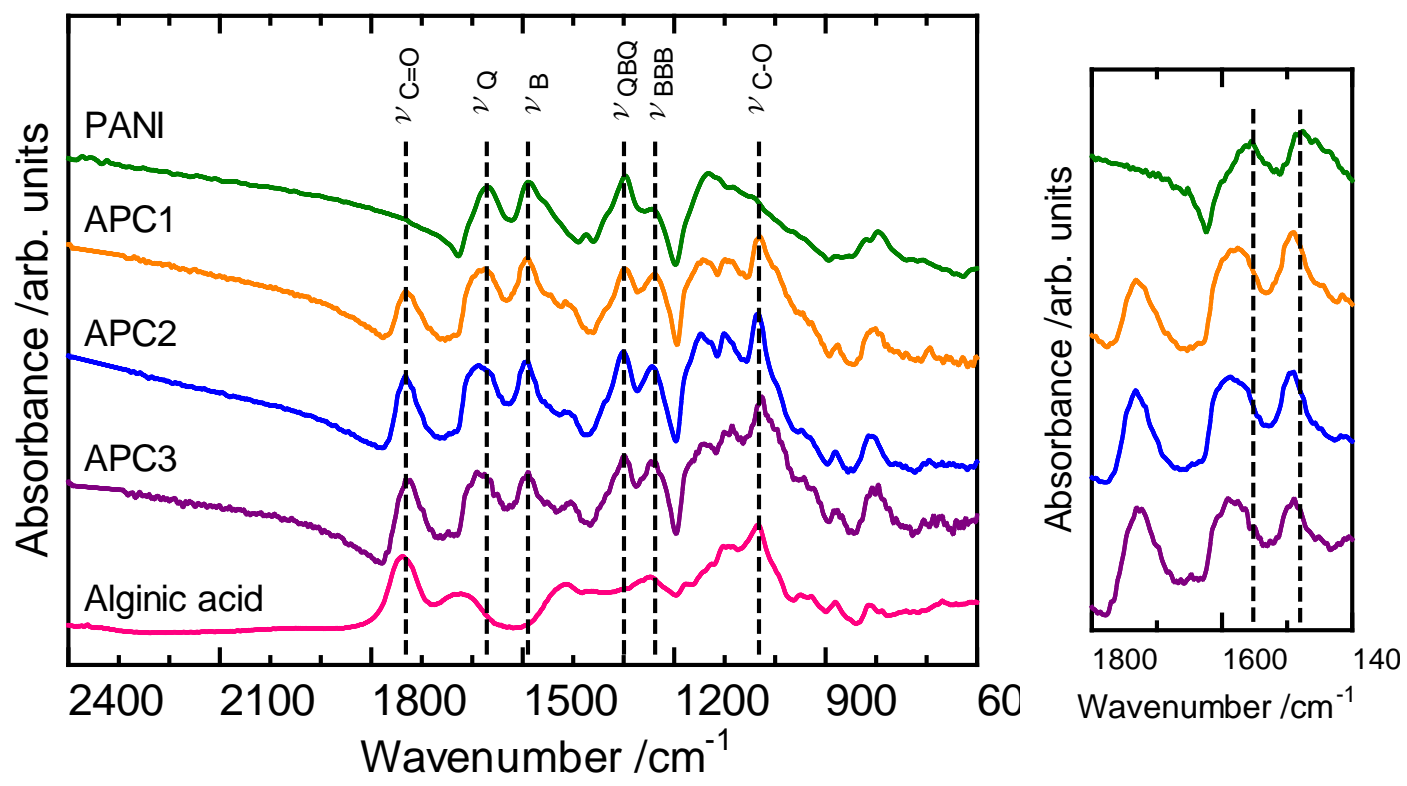

Fig. 1.Infrared (IR) spectra of polyaniline (PANI) and three types of compounds.

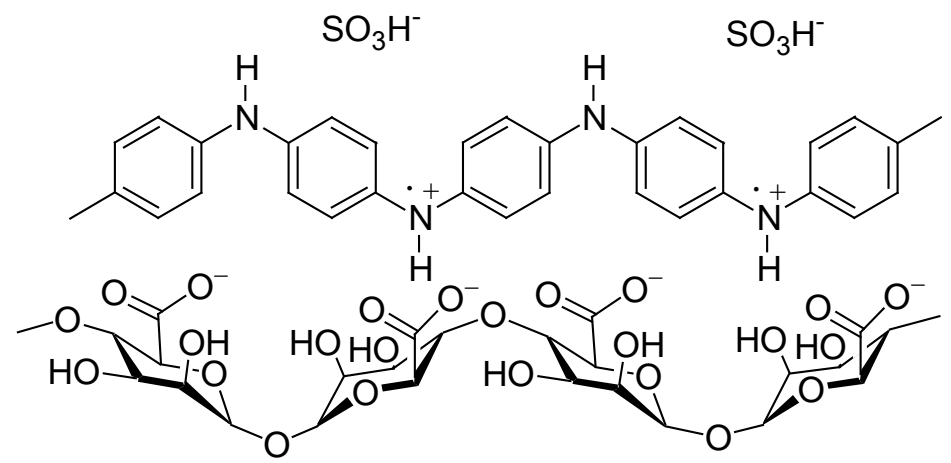

Fig. 2.Composite structure. Cations of polyaniline interacts with anions of alginic acid. 


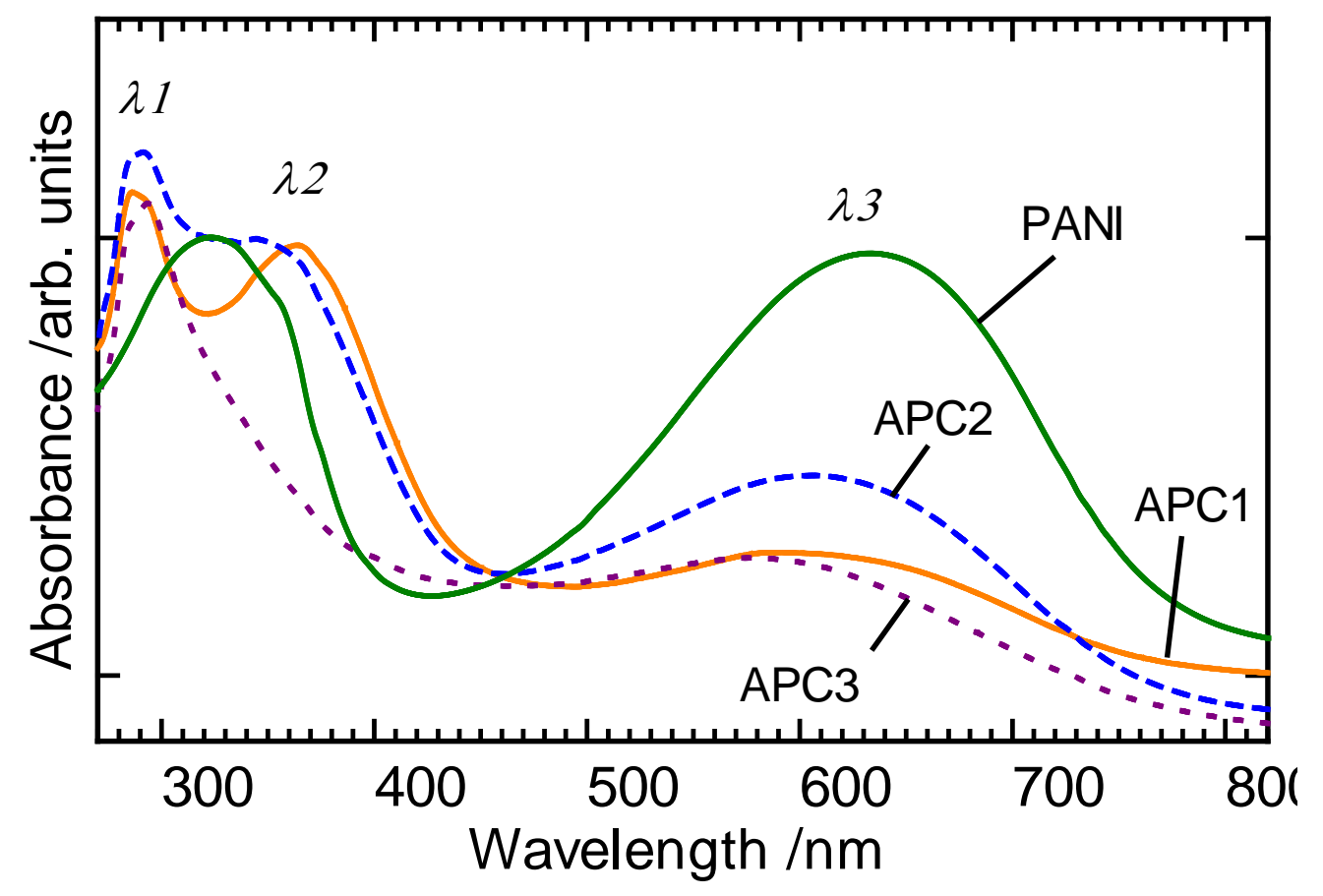

Fig. 3. UV-vis absorption spectra of pure PANI and the series of APCs in NMP solution (0.05 g/L). NMP = N-methylpyrrolidone. 


\section{SYNTHETIC METALS, 194, 47-51(2014)}

Water soluble polyaniline/polysaccharide composite: Polymerization, carbonization to yield carbon micro-bubbles

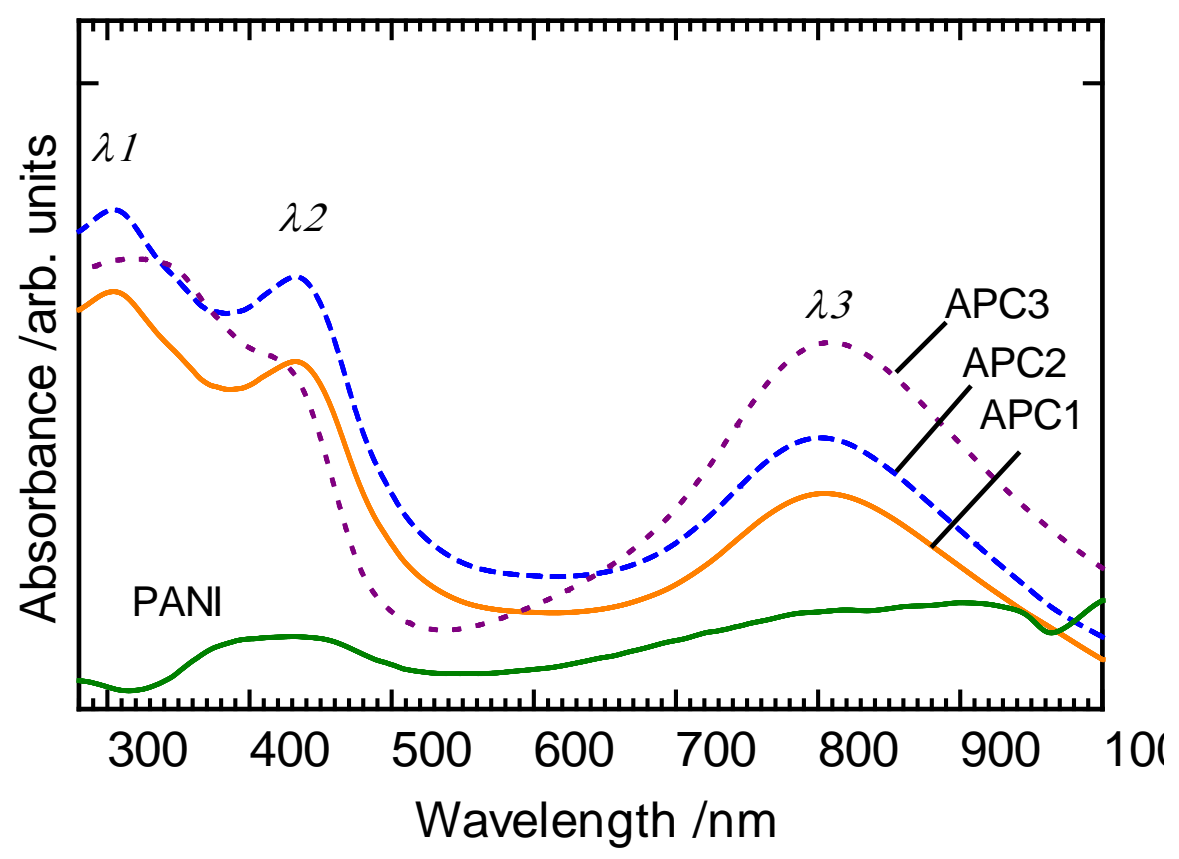

Fig. 4.UV-vis absorption spectra of pure PANI and the series of APCs in water $(0.1 \mathrm{~g} / \mathrm{L})$. APC = composite of PANI and alginic acid

(a)

(c)
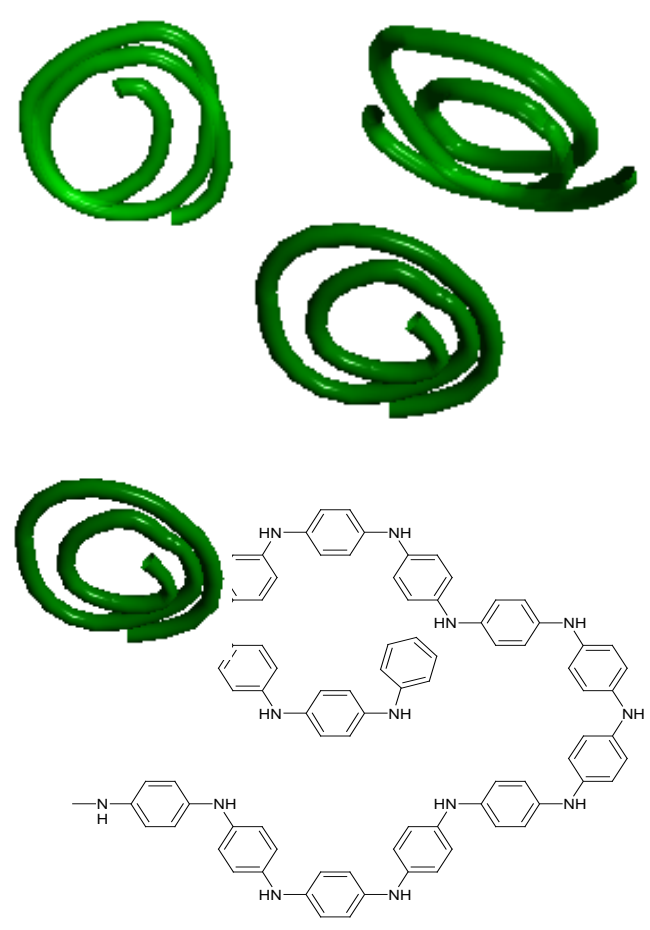

(b)
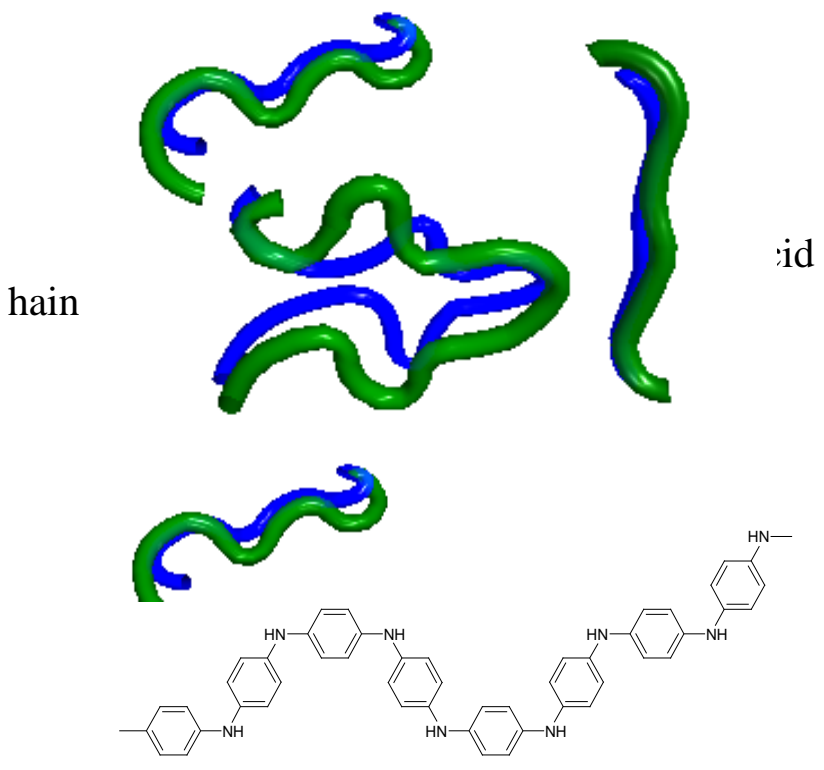

Fig. 5.Plausible forms of compact coil (a,c) and expanded coil of the composite (b). 


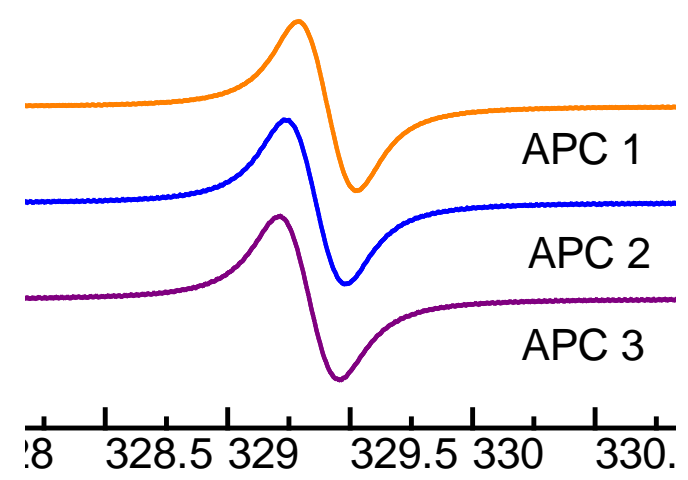

Magnetic field /mT

Fig. 6.Electron spin resonance (ESR) spectra of the composites.

Table 1.ESR measurement results

\begin{tabular}{ccccc}
\hline Polymer & $\boldsymbol{g}$-Value & $\boldsymbol{\Delta} \boldsymbol{H}_{\mathbf{p p}}(\mathbf{m T})$ & $\boldsymbol{N}_{\boldsymbol{s}}(\mathbf{s p i n} / \mathbf{g})$ & Conductivity $\mathbf{( S / \mathbf { c m } )}$ \\
\hline APC 1 & 2.00425 & 0.403 & $1.56257 \times 10^{20}$ & $1.018 \times 10^{-5}$ \\
APC 2 & 2.00419 & 0.440 & $1.41233 \times 10^{19}$ & $7.100 \times 10^{-6}$ \\
APC 3 & 2.00416 & 0.537 & $4.16131 \times 10^{19}$ & $4.674 \times 10^{-6}$ \\
\hline PANI & 2.00357 & 0.366 & $5.73988 \times 10^{21}$ & $2.78 \times 10^{-1}$ \\
\hline
\end{tabular}




\section{SYNTHETIC METALS, 194, 47-51(2014)}

Water soluble polyaniline/polysaccharide composite: Polymerization, carbonization to yield carbon micro-bubbles

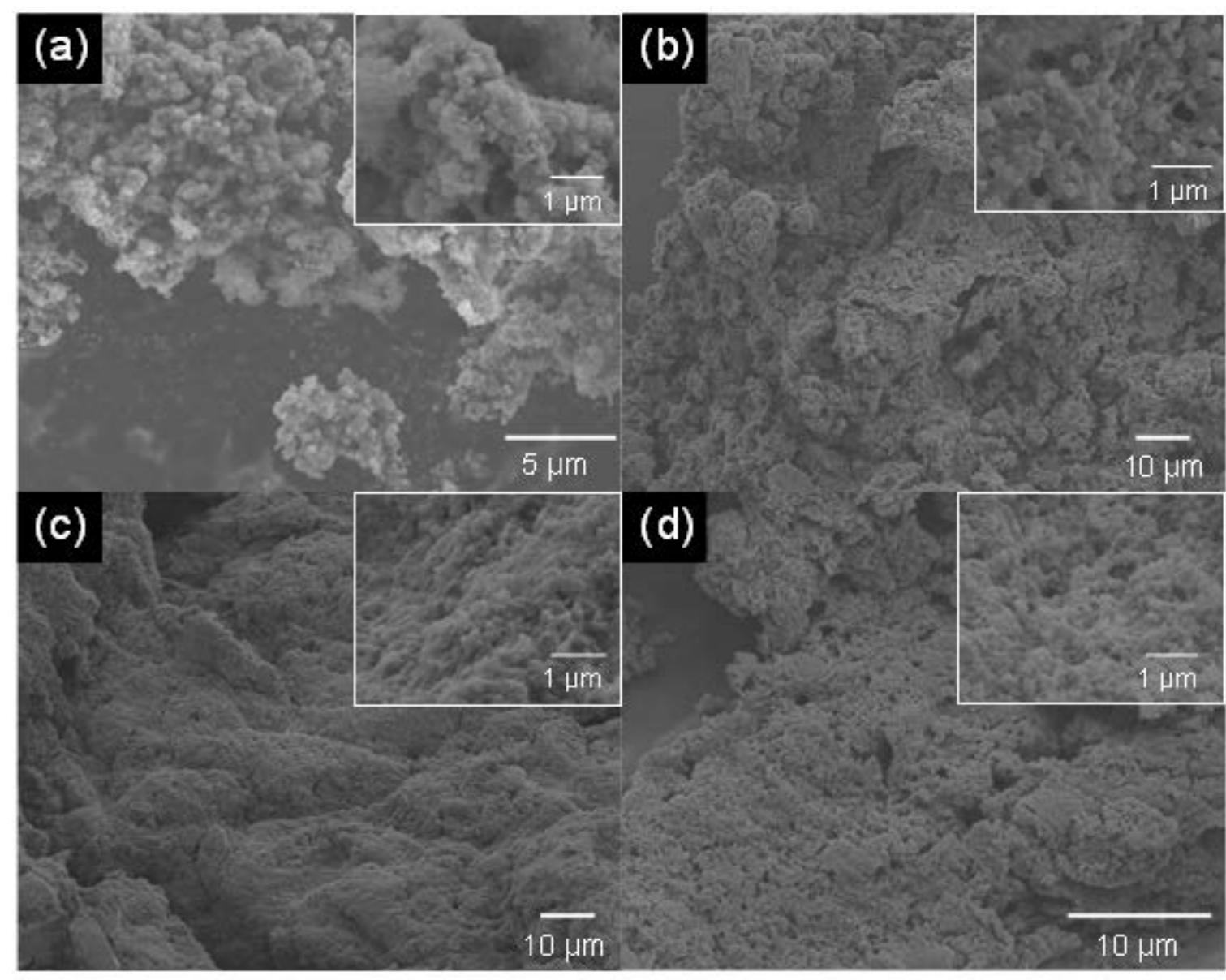

Fig. 7.Scanning electron microscopy (SEM) images of polyaniline (a), APC 1 (b), APC 2 (c), and APC 3 (d). Insets show magnification images.

Table 2.Abundance ratios of APC1-APC3 obtained with EDS

\begin{tabular}{ccccc}
\hline & \multicolumn{5}{c}{ Abundance ratio(\%) } \\
\cline { 2 - 5 } & $\mathrm{C}$ & $\mathrm{N}$ & $\mathrm{O}$ & $\mathrm{S}$ \\
\hline APC1 & 61.5 & 7.5 & 30.8 & 0.2 \\
APC2 & 58.5 & 6.8 & 34.4 & 0.3 \\
APC3 & 59.5 & 5.2 & 35.0 & 0.3 \\
\hline
\end{tabular}


Water soluble polyaniline/polysaccharide composite: Polymerization, carbonization to yield carbon micro-bubbles

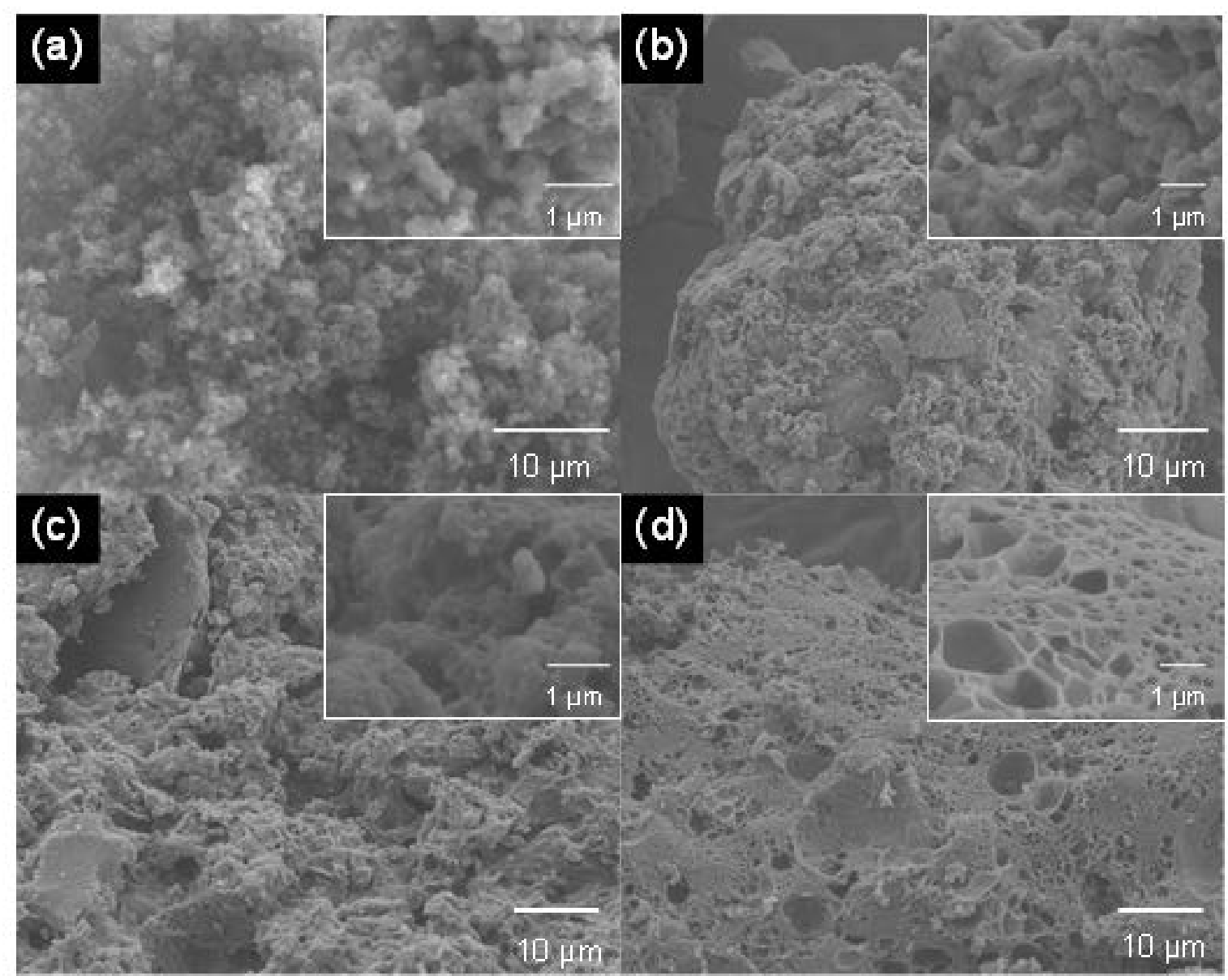

Fig. 8.SEM images of carbonized polyaniline (a), carbonized APC 1 (b), APC 2 (c), and APC 3 (d). Insets show magnification images.

Table 3.Abundance ratios of carbonized APC1-APC3

\begin{tabular}{ccccc}
\hline & \multicolumn{5}{c}{ Abundance ratio(\%) } \\
\cline { 2 - 5 } & $\mathrm{C}$ & $\mathrm{N}$ & $\mathrm{O}$ & $\mathrm{S}$ \\
\hline APC1 & 83.1 & 9.5 & 7.3 & 0.1 \\
APC2 & 81.0 & 8.7 & 10.3 & 0.0 \\
APC3 & 81.4 & 8.8 & 9.8 & 0.0 \\
\hline
\end{tabular}


Supporting information for:

Water soluble Polyaniline/Polysaccharide composite:

Polymerization, Carbonization to Yield Carbon Micro-bubbles

\author{
Kuniharu Nakajima, Kohsuke Kawabata and Hiromasa Goto*
}

Division of Materials Science, Faculty of Pure and Applied Science, University of Tsukuba, Ibaraki, Japan

Correspondence to H. Goto

Tel: +81 029-853-5218

E-mail address: gotoh@ims.tsukuba.ac.jp 
All of the samples for the UV-vis measurements were pre-treated with ultrasonic wave for $40 \mathrm{~min}$ and stirred for $3 \mathrm{~h}$.

Table S1. UV-vis measurements in NMP results

\begin{tabular}{cccccccccc}
\hline & \multicolumn{3}{c}{ Wavelength $(\mathrm{nm})$} & & \multicolumn{3}{c}{ Absorption intensity } & & Intensity ratio \\
\cline { 2 - 3 } & $\lambda 1$ & $\lambda 2$ & $\lambda 3$ & & $\lambda 1$ & $\lambda 2$ & $\lambda 3$ & & $\lambda 3 / \lambda 1$ \\
\hline PANI & 323 & - & 633 & & 1.533 & - & 1.478 & \\
APC1 & 287 & 364 & 589 & & 0.208 & 0.190 & 0.089 & & 0.464 \\
APC2 & 292 & 345 & 607 & & 0.125 & 0.107 & 0.063 & & 0.504 \\
APC3 & 294 & - & 577 & & 0.146 & - & 0.065 & & 0.445 \\
\hline
\end{tabular}

Table S2. UV-vis measurements in water results

\begin{tabular}{cccccccccc}
\hline & \multicolumn{3}{c}{ Wavelength $(\mathrm{nm})$} & & \multicolumn{3}{c}{ Absorption intensity } & & Intensity ratio \\
\cline { 2 - 3 } & $\lambda 1$ & $\lambda 2$ & $\lambda 3$ & & $\lambda 1$ & $\lambda 2$ & $\lambda 3$ & & $\lambda 3 / \lambda 1$ \\
\hline APC1 & 305 & 437 & 805 & & 0.597 & 0.546 & 0.452 & & 0.757 \\
APC2 & 305 & 433 & 802 & & 0.629 & 0.581 & 0.465 & & 0.739 \\
APC3 & 320 & 431 & 808 & & 0.549 & 0.467 & 0.488 & & 0.889 \\
\hline
\end{tabular}


Two broaden absorption bands at around $1560 \mathrm{~cm}^{-1}$ and $1200 \mathrm{~cm}^{-1}$ are observed in the IR, as shown in Fig. S1. These peaks are attributed to $\mathrm{C}=\mathrm{C}$ and $\mathrm{C}-\mathrm{N}$ stretching from cross-linked PANI structure. QBQ or BBB structure was broken by thermal decomposition, however, carbon and trace amount of nitrogen atoms remain in the samples confirmed with EDS measurements (Table 3). The results indicate that the composites became carbon-like materials including nitrogen atoms in its structure [19]. Nitrogen can be derived from pyridinic or pyrrole structure in the resultant carbon. The samples show no ESR signal originated from PANI (Fig. S2). This can be due to dielectric relaxation and skin effect of microwave. Furthermore, unpaired electron of PANI cannot exist stably because of the structural transformation by thermal decomposition. Therefore, we could not obtain ESR signal from carbonized samples. APC1 showed quite weak signals at $342 \mathrm{~nm}$ and $641 \mathrm{~nm}$ in the UV-vis (Fig. S3). The absorption peaks are due to $\pi-\pi^{*}$ transition. The low intensity indicates decrease of conjugation of PANI due to structural transformation by thermal decomposition. Residual fraction of uncarbonized PANI might be presence in the carbonized sample. 


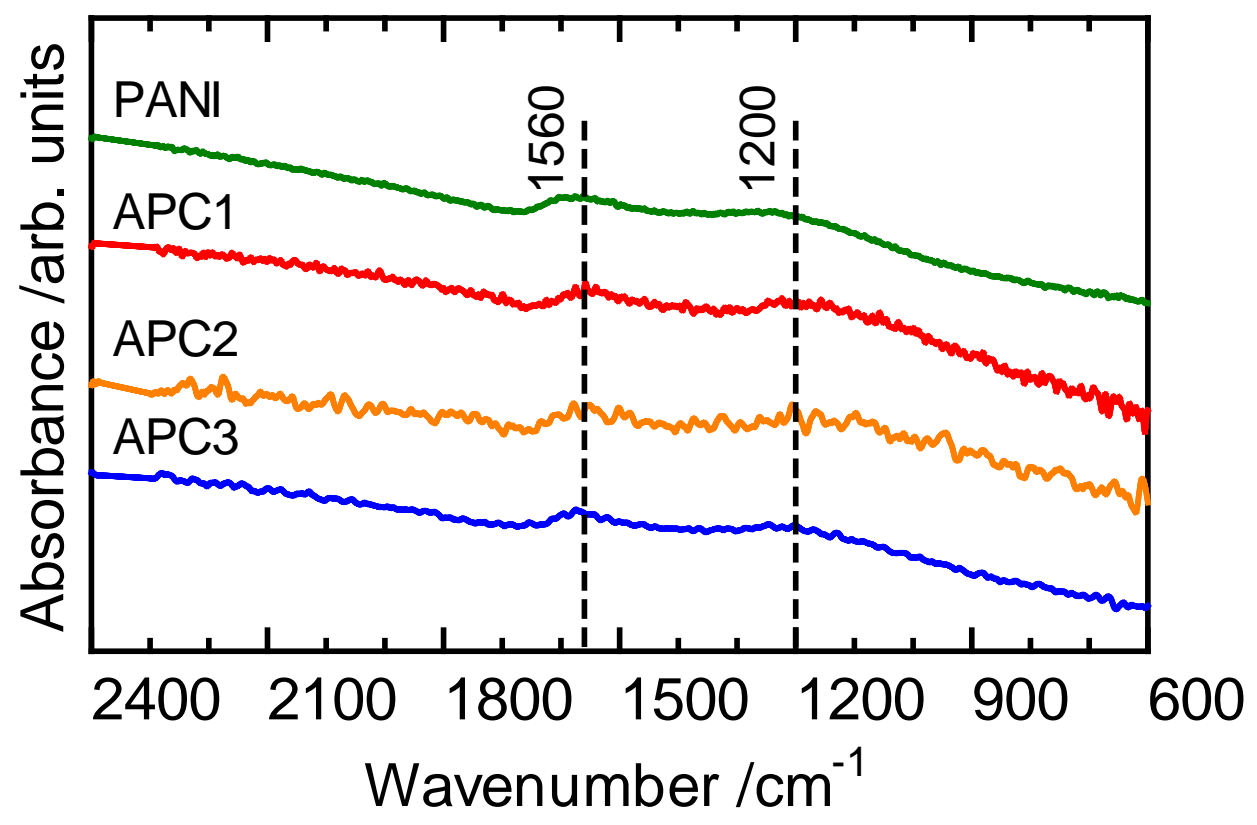

Fig. S1. IR spectra of carbonized PANI and APC1-APC3 


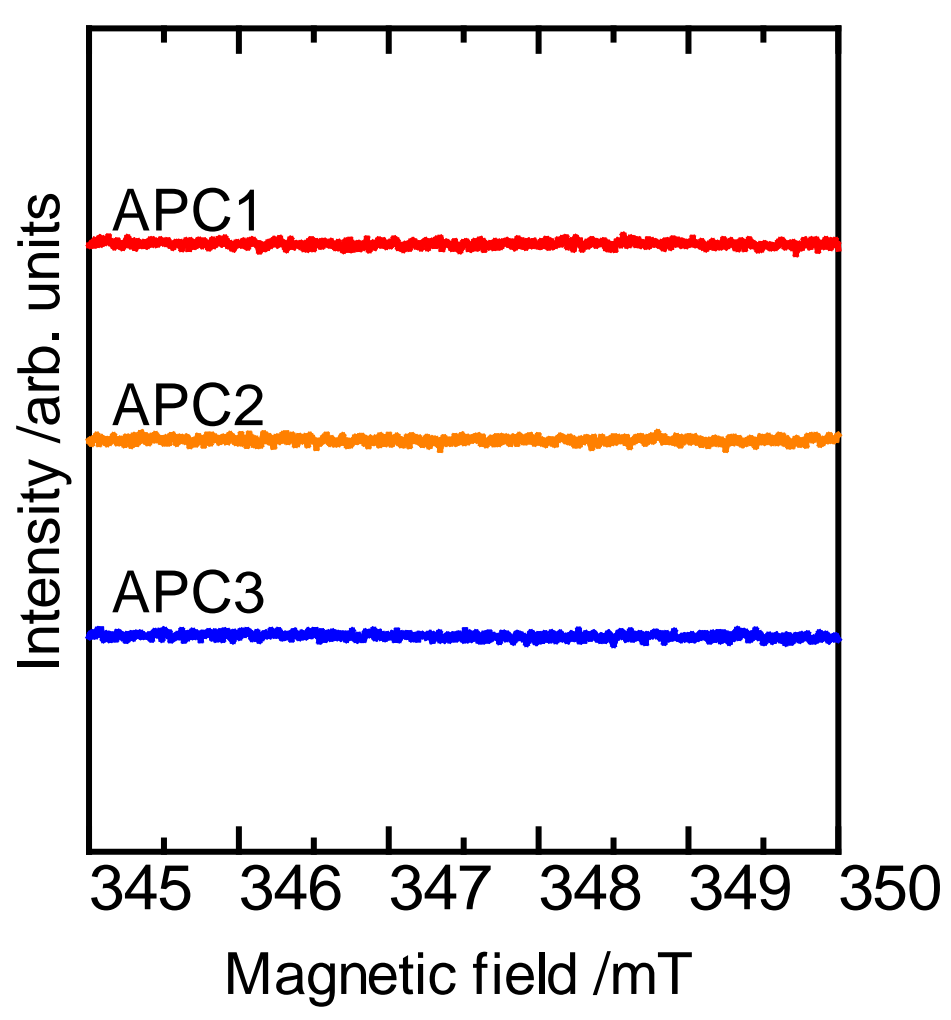

Fig. S2. ESR spectra of carbonized APC1-APC3 


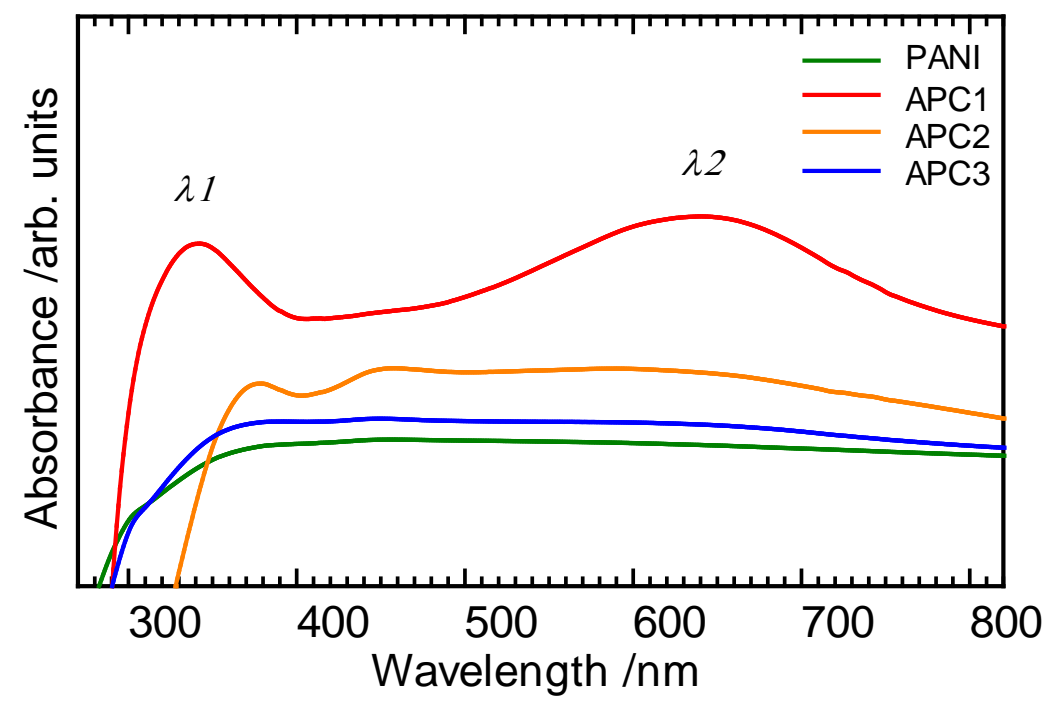

Fig. S3. UV-vis spectra of carbonized PANI and APC1-APC3

Table S3. UV-vis measurement of carbonized APC1-APC3 results

\begin{tabular}{|c|c|c|c|c|c|}
\hline & \multicolumn{2}{|c|}{ Wavelength (nm) } & \multicolumn{2}{|c|}{ Absorption intensity } & \multirow{2}{*}{$\begin{array}{c}\text { Intensity ratio } \\
\lambda 1 / \lambda 1\end{array}$} \\
\hline & $\lambda 1$ & $\lambda 2$ & $\lambda 1$ & $\lambda 2$ & \\
\hline PANI & - & - & - & - & - \\
\hline APC1 & 342 & 641 & 0.014 & 0.015 & 1.071 \\
\hline APC2 & 379 & - & 0.013 & - & - \\
\hline APC3 & - & - & - & - & - \\
\hline
\end{tabular}

